\title{
Enhancement of cytotoxic effect on human head and neck cancer cells by combination of photodynamic therapy and sulforaphane
}

\author{
Sang Joon Lee ${ }^{1}$, Hee-Jun Hwang ${ }^{2}$, Jang-In Shin ${ }^{2}$, Jin-Chul Ahn' ${ }^{2}$ and Phil-Sang Chung ${ }^{1,2}$ \\ ${ }^{1}$ Department of Otolaryngology-Head and Neck Surgery, College of Medicine, Dankook University, Cheonan, Korea \\ ${ }^{2}$ Medical Laser Research Center, Dankook University, Cheonan, Korea
}

\begin{abstract}
Photodynamic therapy (PDT) is a method to treat cancers using photosensitizer and light. PDT has been tried for several tumors. However, the clinical applications are limited by the toxicity of photosensitizer and narrow effect. Sulforaphane (SFN) is a material of isothiocyanate group and known to have anticancer effect. We evaluated the cytotoxic effect of PDT combined with SFN on human head and neck cancer cells. We measured the cell viability, extent of apoptosis and necrosis, reactive oxygen species (ROS) generation and caspase activation. Cell viability was decreased significantly by combination treatment. Cellular apoptosis and necrosis were increased in combination treatment compared to SFN or PDT. ROS generation was also higher in combination treatment than single treatment. In combination treatment group, apoptosis and necrosis were decreased by administration of sodium azide (SA) which is scavenger of ROS. Increased caspase activation in combination treatment was also inhibited by SA. Combination of PDT and SFN led to enhanced cytotoxic effect on head and neck cancer cells. Combination treatment promoted the ROS generation, which induced cell death through activation of caspase pathway.
\end{abstract}

Key words: Photodynamic therapy — Sulforaphane - Reactive oxygen species - Head and neck cancer

\section{Introduction}

Photodynamic therapy (PDT) is a method to treat cancer by irradiating laser with suitable wavelength after administration of the photosensitizer (Biel 1998; Rechtman et al. 2002). The photosensitizer absorbed by the cell is accumulated in several cell sites such as plasma membrane, mitochondria, and lysosomes (Kessel et al. 1995; Berg and Moan 1997; Lam et al. 2001). The cytotoxicity of PDT is mainly caused by reactive oxygen species (ROS). The photosensitizer activated by light transfers energy to tissue oxygen and generates ROS. Because ROS is highly reactive and has short half-life, sites of phototoxicity coincide with the location of photosensitizer accumulation. The ROS generated in the mitochondria is likely to induce apoptosis while ROS in the plasma membrane induces necrosis (Dougherty et al. 1998).

Correspondence to: Phil-Sang Chung, Department of Otolaryngology-Head and Neck Surgery, College of Medicine, Dankook University, 119 Dandae-ro, Cheonan, Chungnam 330-714, Korea E-mail: pschung@dankook.ac.kr
Head and neck cancers are easily assessible for PDT. Because most common type of head and neck cancers is squamous cell carcinoma which arises at the surface mucosa, PDT could be easily applied to the tumor. Also, serious cosmetic problem and functional deficit related to swallowing and communication are frequently accompanied in the conventional treatment of head and neck cancers. PDT has advantages on other treatment modalities including surgery, radiation, or chemotherapy. It is applied repeatedly and it has less side-effect. Photofrin is a representative photosensitizer for PDT used in cancer treatment. Photofrin-PDT gained approval for clinical use in many countries including USA and Canada. It has been successfully applied for many head and neck cancers such as oral, oropharyngeal and laryngeal cancers (Allison et al. 1998; Dougherty et al. 1998; Rigual et al. 2009). We also tried photofrin-PDT for patients with early laryngeal cancer which diffusely recurred after radiation therapy. Photofrin is most commonly used photosensitizer and it has longest clinical history and patient record (Wachowska et al. 2011). In head and neck cancer, there are many clinical cases of 
photofrin-PDT (Keller et al. 1985; Biel 1998). Photofrin was selected because it may have more clinical significance than other photosensitizers and suitable for study using head and neck cancer cells. However, the limitation of PDT is phototoxicity and narrow effect. It would be very desirable if we enhance the PDT effect by combining modalities. If the combination therapy could induce enhanced cytotoxicity, it would be possible to achieve the similar cytotoxic effect with low intensity of each treatment modality. This would potentiate the clinical efficacy of PDT with less toxicity. Sulforaphane (SFN) is a molecule of isothiocyanate group and included in cruciferous vegetables (Nishikawa et al. 2009). SFN is known to have anticancer effect (GametPayrastre et al. 2000; Chiao et al. 2002). ROS is related to the initiation of SFN-induced cell death (Singh et al. 2005; Kim et al. 2006; Choi et al. 2008). This study was designed to evaluate the anticancer effect of combination therapy of PDT and SFN.

\section{Materials and Methods}

\section{Cell line and chemicals}

The human head and neck cancer cell line (AMC-HN3) which was derived from laryngeal carcinoma of 63-year-old male was used (kindly donated by Asan Medical Center, Seoul, Korea) (Kim et al. 1997). Cells were cultured in RPMI 1640 media (HyClone, South Logan, UT, USA) supplemented with $10 \%$ fetal bovine serum (FBS) (Gibco, BRL) and $1 \%$ streptomycin/penicillin (Gibco, BRL) in a humidified incubator $\left(5 \% \mathrm{CO}_{2}, 95 \%\right.$ air $)$ at $37^{\circ} \mathrm{C}$.

The photosensitizer used for PDT is porfimer sodium, sold as Photofrin (QTL Photo Therapuetics Inc., Canada). It was diluted in Dulbecco's phosphate buffered saline (DPBS) (Gibco, BRL) at a concentration of $10 \mathrm{mg} / \mathrm{ml}$ in refrigerator at $4^{\circ} \mathrm{C}$ in the dark for storage and diluted with culture medium at a concentration of $1 \mathrm{mg} / \mathrm{ml}$ before used. SFN was purchased from Sigma (St. Louis, MO, USA) and $10 \mathrm{mM}$ of stock solution was stored at $4^{\circ} \mathrm{C}$ in the dark. 3-[4,5-dimethylthiazol-2-yl]-2,5-diphenlyl-tetrazolium bromide (MTT), dimethyl sulfoxide (DMSO), Hoechst 33342 dye, propidium iodide (PI) dye and sodium azide (SA) were purchased from Sigma-Aldrich (St. Louis, MO, USA). Bradford dye reagent was supplied by Bio-rad (Hercules, CA, USA). Caspase-3, caspase- 8 and poly(ADPribose) polymerase (PARP) were from Calbiochem (San Diego, CA, USA); caspase-9 was from Santa Cruz Biotechnology (Santa Cruz, CA, USA); Glyceraldehyde 3-phosphate dehydrogenase (GAPDH) was from Abcam (Cambridge, UK); and 2',7'-dichlorodihydrofluorescein diacetate (H2DCFDA) was from Molecular Probes (Eugene, OR, USA).

\section{Treatment protocol and cell viability assay}

AMC-HN3 cells were diluted at a concentration $5 \times 10^{4}$ cells/ $\mathrm{ml}$ and inoculated into a 96-well microplate at a volume of $100 \mu \mathrm{l}$. Cells were incubated for 24 hours in an incubator $(5 \%$ $\mathrm{CO}_{2}, 37^{\circ} \mathrm{C}$ ) for attachment to well. The cells were grouped into four; control, PDT group, SFN group and PDT+SFN group. For PDT group, various concentrations of photofrin $(0-50 \mu \mathrm{g} / \mathrm{ml})$ were treated to the cells. After incubation for 6 hours in dark conditions, the cells were irradiated with $630 \mathrm{~nm}$ diode laser at an intensity of $2.0 \mathrm{~J} / \mathrm{cm}^{2}$ for $15 \mathrm{~min}$ utes. After irradiation, cells were further incubated in the dark conditions for 24 hours. For SFN group and PDT+SFN group, cells were treated with SFN at various concentrations and incubated in the dark conditions for 24 hours before PDT or not.

Cell viability was measured by MTT assay. SFN treatment and/or PDT were applied according to the treatment protocol described above. Twenty four hours after media change, $50 \mu \mathrm{l}$ of MTT solution was added to the cells and cells were incubated for 4 hours. After incubation, media was removed and $150 \mu \mathrm{l}$ of DMSO was added to each wells. The wells were shook for 1 minute to dissolve the formazan crystal. Absorbance at $540 \mathrm{~nm}$ was measured by microplate reader (Bio-rad 550, Hercules, CA). The percentage of cell viability was calculated by mean absorbance in the test well divided by control well.

\section{Confocal microscopic examination}

Apoptosis or necrosis was measured by Hoechst and PI double staining. Cells were seeded on 6 -well plate $\left(1 \times 10^{5}\right.$ cells $/ \mathrm{ml}$ ) at a volume of $2 \mathrm{ml}$ and treated by above protocol. Twenty four hours after laser irradiation, cells were incubated with Hoechst $33342(2 \mu \mathrm{g} / \mathrm{ml})$ for 30 minutes. After media change, the cells were incubated with PI $(2 \mu \mathrm{g} / \mathrm{ml})$ for 10 minutes. The stained cells were observed to measure the cellular apoptosis and necrosis using confocal microscope (Zeiss LSM510 META, Germany). Nuclear shrinkage, condensation and fragmentation in the cells stained bright blue by Hoechst were considered as apoptosis. Cells whose nuclei are stained red by PI were considered as necrosis. To compare the extent of apoptosis and necrosis in each groups, photos were taken randomly at five different points in one cultivation dish by confocal microscope (X100) and cells showing apoptosis or necrosis were counted. Percentage of apoptotic and necrotic cells were calculated by numbers of apoptotic or necrotic cells divided by total cells.

To measure the intracellular ROS generation, H2DCFDA was used as the oxidant sensitive fluorescent probe. Cells were incubated in 6 -well plate $\left(1 \times 10^{5}\right.$ cells $\left./ \mathrm{ml}\right)$ at a volume of $2 \mathrm{ml}$ and treated by protocol. After laser irradiation, $20 \mu \mathrm{M}$ 
of H2DCFDA was added to the culture media and cells were incubated for 30 minutes. The level of green fluorescence was measured by confocal microscope at $488 \mathrm{~nm}$ excitation wavelength.

To evaluate the causal relation between intracellular ROS and the induction of apoptosis and necrosis, SA - inhibitor of ROS - was applied. Cells were seeded to 6 -well plate $(1 \times$ $10^{5}$ cells $/ \mathrm{ml}$ ) and incubated for 24 hours for attachment to the well. For PDT+SFN group, SA was added to the media before SFN treatment. Twenty-four hours after laser irradiation, level of ROS generation, apoptosis and necrosis were measured using confocal microscope in PDT+SFN group and SA-treated PDT+SFN group.

\section{Fluorescence activated cell sorter (FACS) analysis}

Quantitative analysis of ROS generation was performed using FACS. Cells were treated as protocol and suspended cells were incubated with $20 \mu \mathrm{M}$ H2DCFDA in $2 \mathrm{ml}$ of DPBS for $30 \mathrm{~min}$ at $37^{\circ} \mathrm{C}$. Cells were subjected to FACSCalibur (Becton Dickinson, San Jose, CA, USA) and measured using FL1-H (530 nm) channel. Data were analyzed with CELLQuest program (Becton Dickinson, San Jose, CA, USA).

\section{Western blot}

We analyzed the caspase- 8 and -9 which represent the extrinsic and intrinsic pathway of apoptosis and caspase- 3 and PARP which located in common final step of apoptosis. To detect the expression of caspase proteins after PDT and/or SFN treatment, cells were grown on $100 \mathrm{~mm}$ of diameter dishes (Sarstedt, NC) and series of treatment were conducted. Cells were washed twice with cold DPBS and lysed with cold Ripa buffer (50 mM Tris- $\mathrm{HCl}, \mathrm{pH} 8.0$, $1 \%$ NP-40, 0.5\% sodium deoxycholate, $150 \mathrm{mM}$ sodium chloride, $0.1 \%$ sodium dodexyl sulfate with protease and phosphatase inhibitor cocktail, Sigma, MO) and agitated at $4^{\circ} \mathrm{C}$ using shaking machine for 30 minutes, and then centrifuged at $13,000 \mathrm{rpm}$ for 30 minutes at $4^{\circ} \mathrm{C}$. The supernatant was obtained and protein concentration was determined with a Bradford assay (Bio-rad, CA). Equivalent amounts of protein from each sample were subjected to gel electrophoresis on 10\% SDS-PAGE and NuPAGE 4-12\% Bis-Tris gel. The protein was transferred to Polyvinylidene fluoride (PVDF) membranes (Bio-rad, Hercules, CA, USA) and then blocked with $10 \%$ skimmed milk for 1 hour at room temperature. After treated with primary antibodies (caspase-3, -8, -9 and PARP) for 1 hour at room temperature, the membrane were probed with horseradish peroxidase-conjugated secondary IgG antibody for 1 hour. The protein band was detected with an image analyzer (Kodak, Japan).
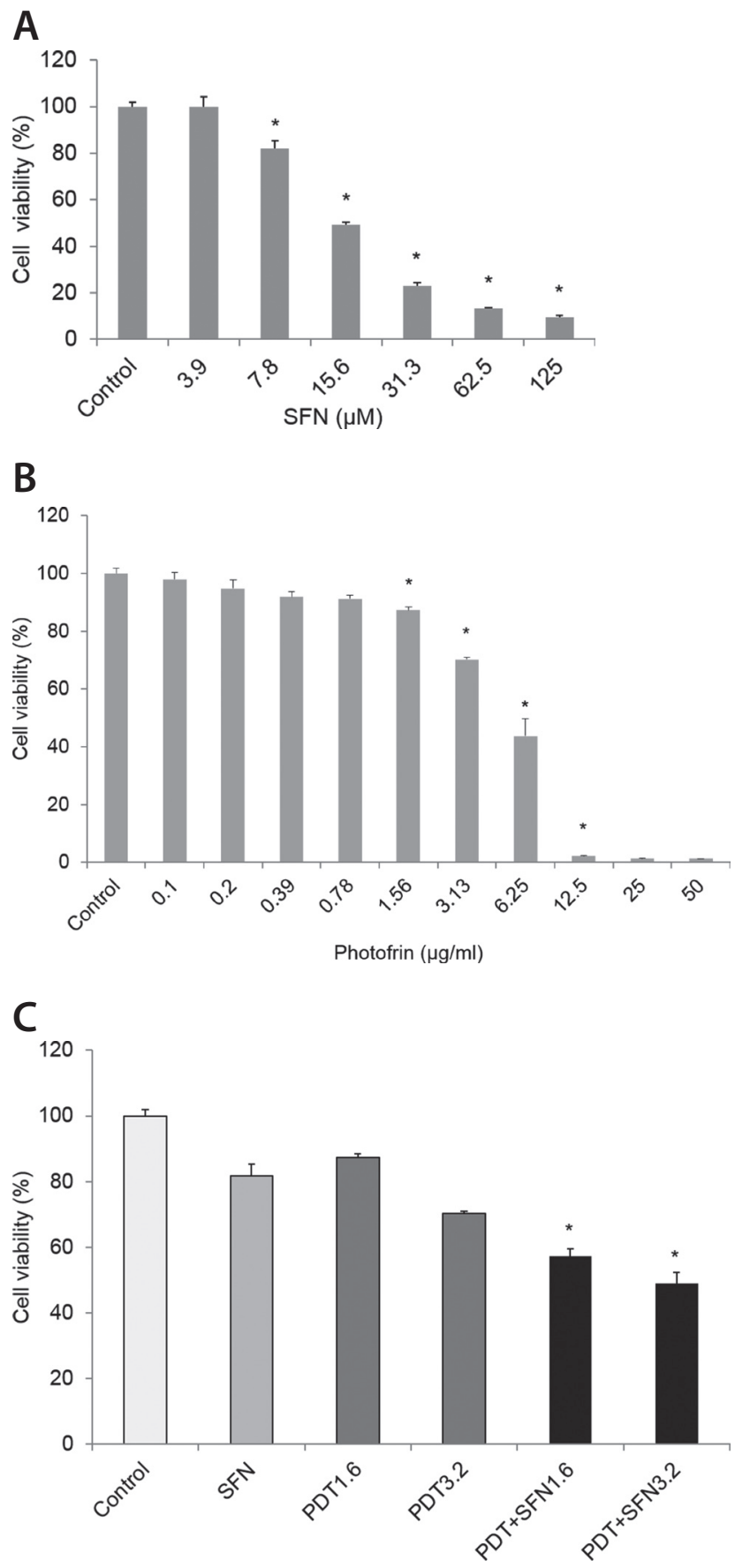

Figure 1. Cytotoxicity of each treatment groups on AMC-HN3 human head and neck cancer cells measured by MTT assay. A. Sulforaphane (SFN). Cell viability was decreased significantly as the concentration of SFN was increased. B. Photodynamic therapy (PDT). Cell viability was also decreased dose-dependently as the concentration of photofrin, a photosensitizer, was increased. C. Combination of PDT and SFN. PDT combined with SFN showed significantly greater cytotoxicity than single treatment groups. PDT1.6, $1.6 \mu \mathrm{g} / \mathrm{ml}$ of photofrin; PDT3.2, 3.2 $\mu \mathrm{g} / \mathrm{ml}$ of photofrin; PDT+SFN1.6, 7.8 $\mu \mathrm{M}$ of SFN and $1.6 \mu \mathrm{g} / \mathrm{ml}$ of photofrin; PDT+SFN3.2, $7.8 \mu \mathrm{M}$ of SFN and $3.2 \mu \mathrm{g} / \mathrm{ml}$ of photofrin; ${ }^{\star} p<0.05$. 
A

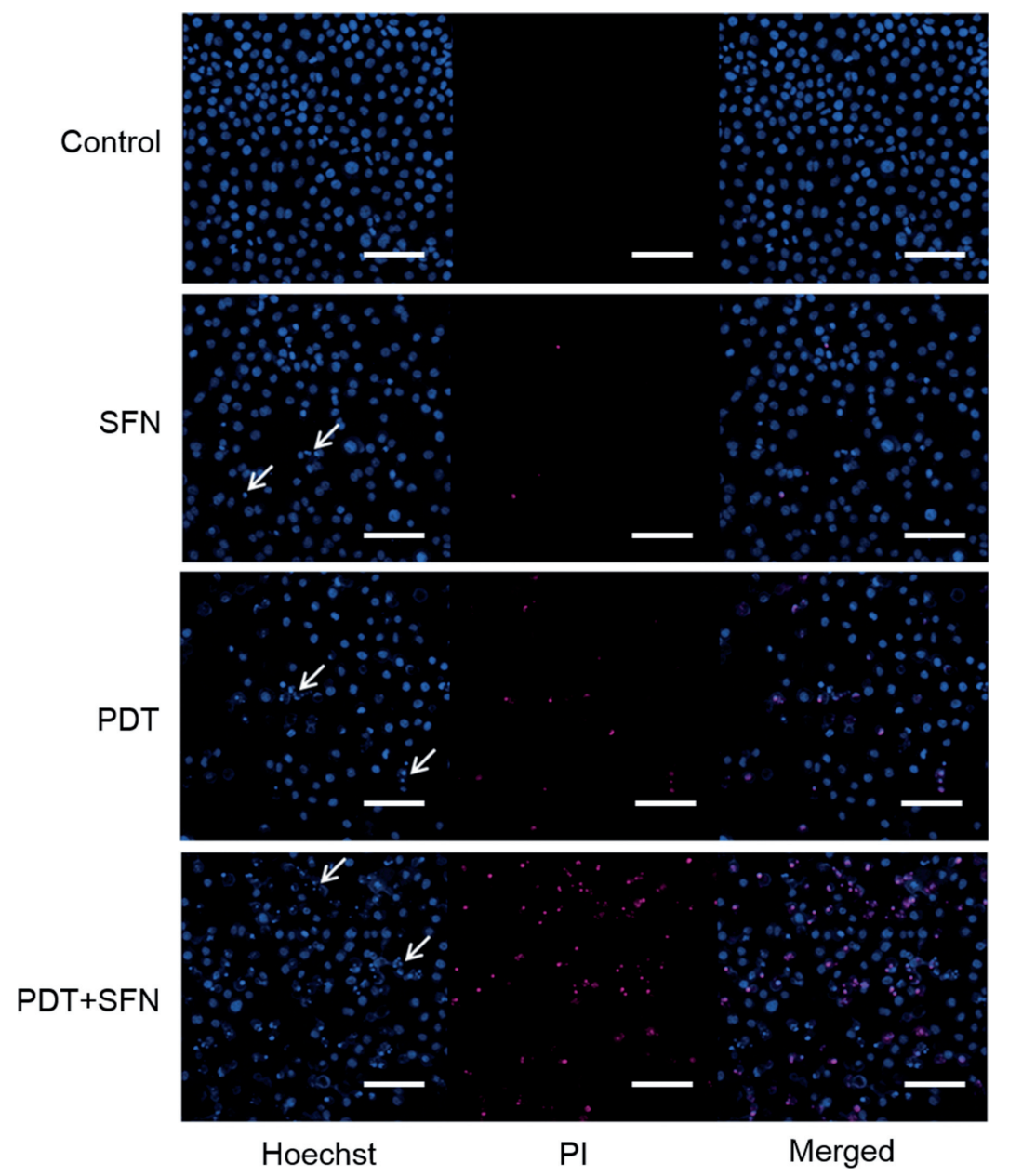

B
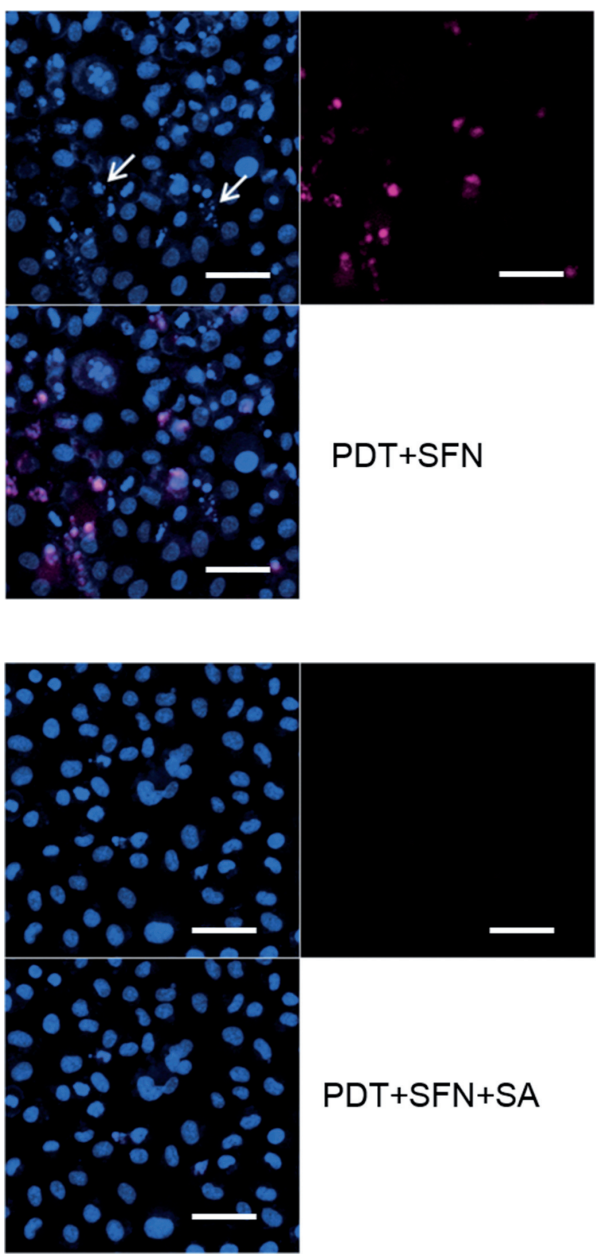

C

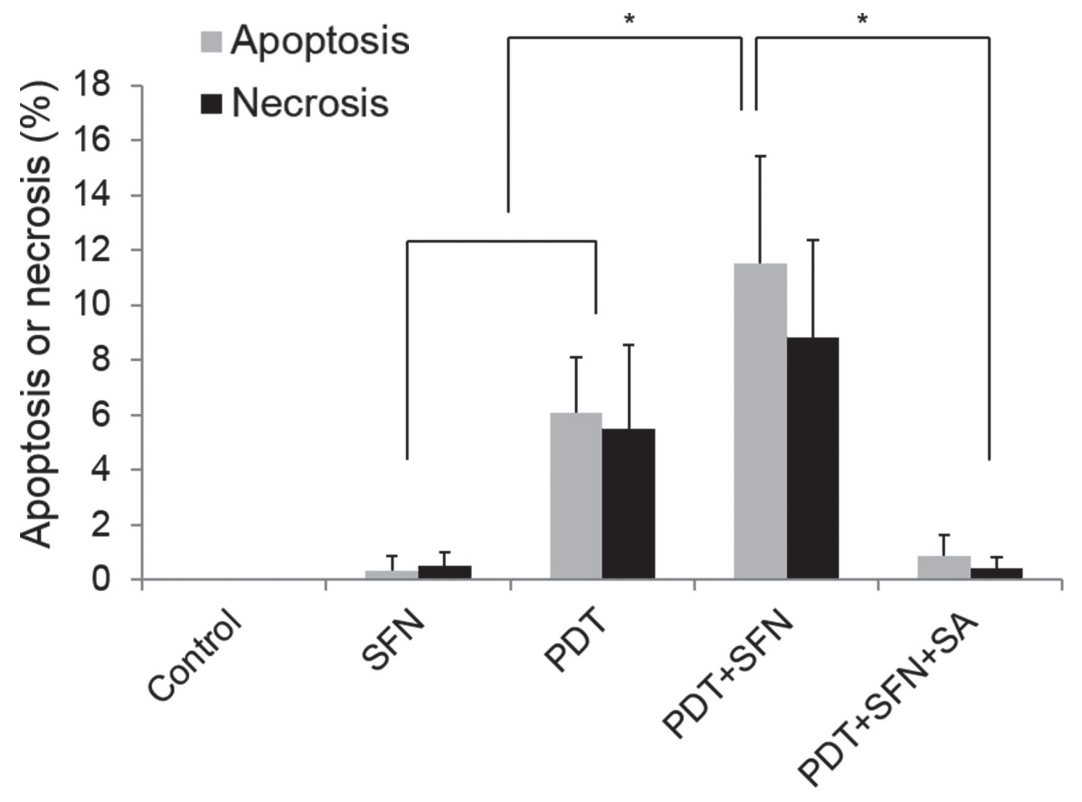

Figure 2. Evaluation of apoptosis and necrosis using Hoechst 33342 and PI double staining. Apoptotic cells were observed as fragmented small dots which were stained bright blue due to the condensation or fragmentation of nuclear material in Hoechst staining (white arrow) and necrotic cells were stained red by PI staining. A. Apoptosis and necrosis were increased in PDT+SFN group compared to PDT or SFN group (scale bar $=100 \mu \mathrm{m})$. B. When ROS generation was inhibited by sodium azide (SA), a scavenger of ROS, in PDT+SFN group, apoptosis and necrosis were decreased (scale bar = $50 \mu \mathrm{m})$. C. Percentage of apoptosis and necrosis was higher in the PDT+SFN group with statistical significance $\left({ }^{*} p<0.05\right)$. SFN, sulforaphane; PDT, photodynamic therapy. 


\section{Statistical analysis}

Statistical analysis was performed using SPSS 13.0 for windows (SPSS Inc., Chicago, USA). The data were expressed as the mean \pm standard deviation. Differences between single treatment group and combination treatment group were analyzed using t-test and Mann-Whitney $\mathrm{U}$ test. $p$-value less than 0.05 was considered significant.

\section{Results}

\section{Cytotoxicity of SFN, PDT and PDT combined with SFN}

At various SFN concentrations, cell viability of AMC$\mathrm{HN} 3$ cells was decreased as the concentration of SFN was increased. Cytotoxic effect was not observed at $3.9 \mu \mathrm{M}$ of SFN concentration, however, from $7.8 \mu \mathrm{M}$ of SFN, cell viability was statistically lower than control. Cell viability was $81.9 \pm 3.6 \%$ at $7.8 \mu \mathrm{M}, 49.4 \pm 1.1 \%$ at $15.6 \mu \mathrm{M}$, and $23.0 \pm 1.4 \%$ at $31.3 \mu \mathrm{M}$ of SFN concentration $(p<0.05)$ (Fig. 1A). Since 7.8 $\mu \mathrm{M}$ is the lowest effective concentration of SFN, we selected this concentration for combination therapy. The significant cytotoxic effect of PDT was observed from $1.6 \mu \mathrm{g} / \mathrm{ml}$ of photofrin concentration. Cytotoxicity of PDT was also increased dose-dependently on the concentration of photofrin (Fig. 1B). The cytotoxicity of combination therapy was compared to the single treatment. At $7.8 \mu \mathrm{M}$ of SFN and $1.6 \mu \mathrm{g} / \mathrm{ml}$ of photofrin concentration, cell viability was $81.9 \pm 1.1 \%$ in SFN group and $87.3 \pm 1.1 \%$ in PDT group. In PDT+SFN group, cell viability was $57.4 \pm 3.3 \%$. At $7.8 \mu \mathrm{M}$ of SFN and $3.2 \mu \mathrm{g} / \mathrm{ml}$ of photofrin concentration, cell viability was $70.3 \pm 0.8 \%$ in PDT group. However, cell viability of PDT+SFN group was $49.0 \pm 3.3 \%(p<0.05)$ (Fig. 1C), which showed significantly enhanced cytotoxicity over single treatment groups.

\section{Measurement of apoptosis and necrosis}

In evaluating the extent of apoptosis and necrosis in each groups, we selected $7.8 \mu \mathrm{M}$ of SFN and $3.2 \mu \mathrm{g} / \mathrm{ml}$ of photofrin concentrations considering the cytotoxicity profile of SFN and PDT. In Hoechst staining, apoptotic cells whose nucleus looked fragmented or condensed were observed in SFN, PDT and PDT+SFN group. Especially, apoptosis was measured most frequently in PDT+SFN group. In PI staining, necrotic cells whose nucleus stained red were observed after PDT or SFN treatment and also measured most frequently in PDT+SFN group compared to SFN or PDT group. Increased apoptosis and necrosis in PDT+SFN group were well visualized in merged image (Fig. 2A). When $\mathrm{PDT}+\mathrm{SFN}$ group was treated by the $10 \mathrm{mM}$ of SA, enhance- ment of apoptosis and necrosis was inhibited (Fig. 2B). In another set of experiment done in the same concentrations, apoptotic and necrotic cells were counted as described above. Percentage of apoptosis and necrosis was each $0.3 \pm 0.6 \%$ and $0.5 \pm 0.5 \%$ in SFN, $6.1 \pm 2.0 \%$ and $5.5 \pm 3.1 \%$ in PDT, 11.5 $\pm 3.9 \%$ and $8.8 \pm 3.5 \%$ in PDT+SFN group. PDT combined with SFN induced higher rate of apoptosis and necrosis with statistical significant difference. The enhanced apoptosis and necrosis in PDT+SFN group was blocked by SA $(0.9 \pm 0.8 \%$, $0.4 \pm 0.4 \%$ ) (Fig. 2C).

\section{Induction of ROS generation}

At the $7.8 \mu \mathrm{M}$ of SFN and $3.2 \mu \mathrm{g} / \mathrm{ml}$ of photofrin concentration, green fluorescence of ROS was the highest in the PDT+SFN group, followed by PDT and SFN group (Fig. 3A). When the cells were treated by $10 \mathrm{mM}$ of SA in PDT+SFN group, green fluorescence of ROS was decreased compared to the untreated PDT+SFN group (Fig. 3B). Production and blocking of ROS was quantitatively measured using FACS. On FACS analysis, PDT+SFN group showed higher mean fluorescence intensity (MFI) than other groups (Fig. 4A). Besides, SA-treated PDT+SFN group showed lower MFI than untreated group (Fig. 4B). This result confirmed that $\mathrm{PDT}+\mathrm{SFN}$ group enhanced the ROS production compared to single treatment groups and activity of ROS was effectively blocked by SA.

\section{Expression of caspase pathway}

To confirm the activation of caspase pathway, expression of caspase-3, -8, -9, and PARP was measured by Western blot analysis. The downstream caspase pathway was activated definitely in PDT and PDT+SFN group and the extent of expression was higher in $\mathrm{PDT}+\mathrm{SFN}$ group. In addition, activated downstream caspase pathway was inhibited in SA-treated PDT+SFN group (Fig. 5). From these results, we confirmed that apoptotic process was more activated in PDT+SFN group than single treatment groups and ROS induced caspase pathway to apoptosis in PDT+SFN group.

\section{Discussion}

PDT has been used for cancer treatment since 1980s. PDT using photofrin as a photosensitizer gained FDA approval in US for the palliative treatment of obstructed esophageal and bronchial cancer, but it has been tried for early stage cancer with curative intent (Pass 1993). In head and neck cancers, PDT has been applied for early stage oral or laryngeal cancers and overall rate of complete remission was $85 \%$ since Keller reported first three cases of oral cancer successfully treated by 
PDT (Keller et al. 1985; Biel 1998). The advantages of PDT have less side-effect, possibility of combined treatment with other treatment modalities and no limitation theoretically in treatment number of times. The main anticancer effect of PDT is derived from ROS generation in the tumor cells. Most ROS production occurs within the mitochondria. ROS produced within the mitochondria causes the mitochondrial depolarization and permeabilization. Finally, caspase-3 activation results in apoptotic cell death (Lam et al. 2001). Whether cell death is by apoptosis or necrosis, it is related to the power of irradiation in PDT (Takahashi et al. 2003). In clinical setting, the efficacy of PDT is frequently limited by the phototoxicity and shallow effect range. SFN is known to suppress the growth of cultured cancer cells as well as tumor xenografts in vivo by cell cycle arrest and apoptosis (Gamet-Payrastre et al. 2000). The signaling pathway leading to cell death was not clearly understood but some reports indicate that $\mathrm{SFN}$-induced cell death is initiated by the formation of ROS (Singh et al. 2005; Kim et al. 2006; Choi et al. 2008). ROS initiates the serial process composed of disruption of mitochondrial membrane potential, activation of caspase- 9 and apoptosis. They also postulated the pathway by caspase- 8 (Singh et al. 2005).

In our study, we explored whether combination of PDT and SFN could enhance the anticancer effect. From the cell viability graph of SFN, we determined the minimum effective dose of SFN as $7.8 \mu \mathrm{M}$. We also selected two concentrations of photofrin, which are $1.6 \mu \mathrm{g} / \mathrm{ml}$ and $3.2 \mu \mathrm{g} / \mathrm{ml}$. As shown in Figure 1C, combination of SFN and PDT had enhanced cytotoxic effect over single treatment of SFN or PDT. We also confirmed the increased cytotoxicity

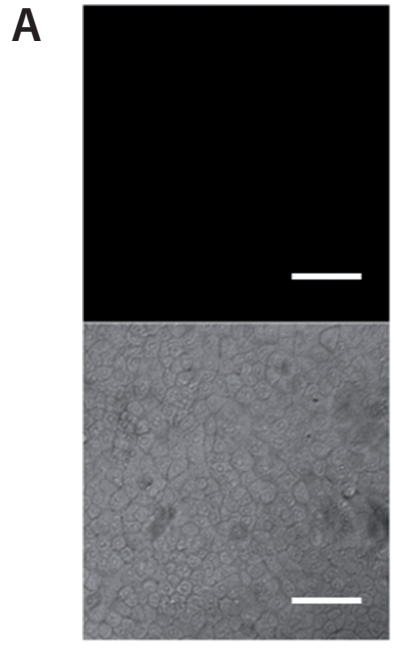

Control

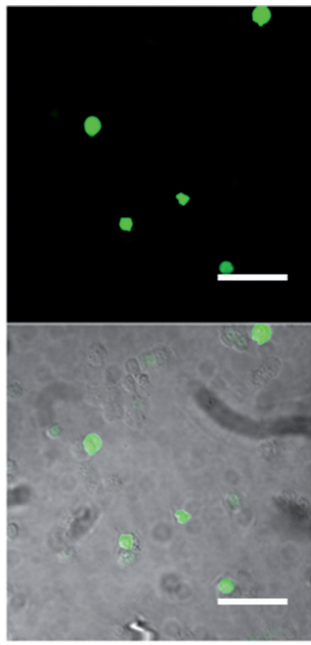

SFN
B
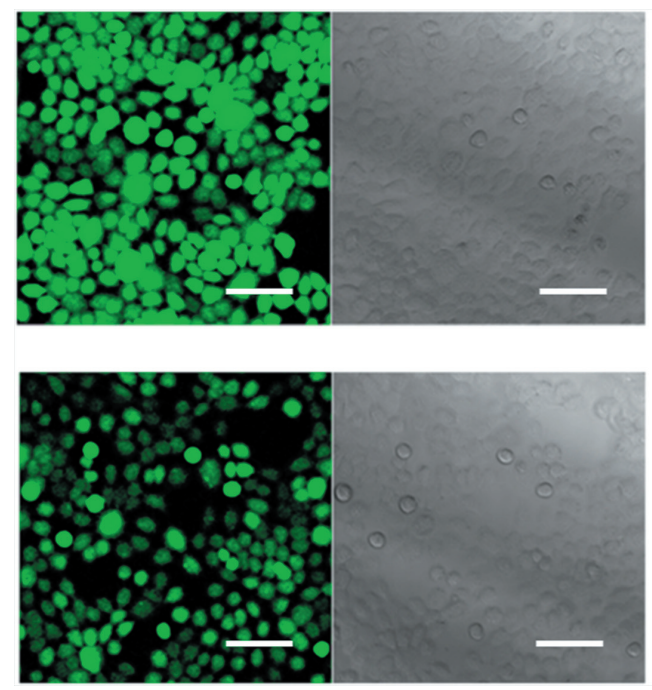

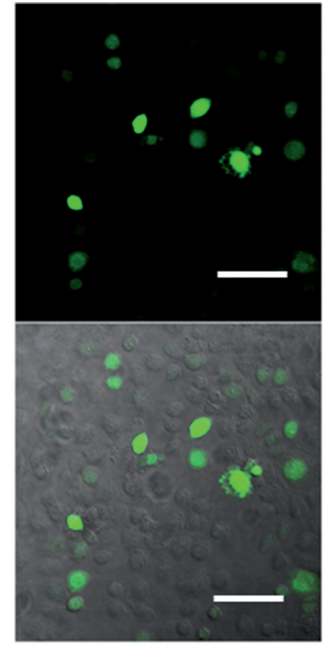

PDT

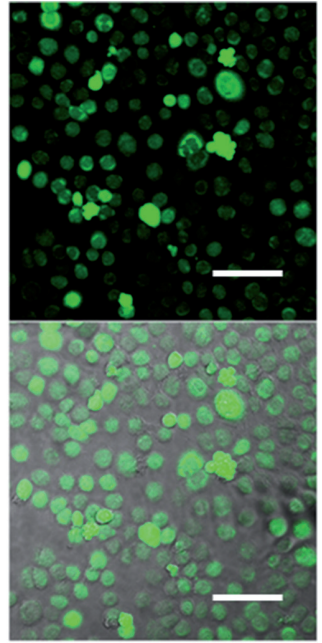

PDT+SFN

PDT + SFN

$\mathrm{PDT}+\mathrm{SFN}+\mathrm{SA}$

Figure 3. Evaluation of ROS generation using H2DCFDA fluorescent probe. A. The green fluorescence of ROS was the highest in the PDT+SFN group, followed by PDT and SFN group (scale bar = $50 \mu \mathrm{m}$ ). B. ROS generation was decreased by the administration of SA in PDT+SFN group (scale bar $=50 \mu \mathrm{m}$ ). SFN, sulforaphane; PDT, photodynamic therapy. 
microscopically. PDT combined with SFN induced much more apoptotic and necrotic cells than the single treatment of PDT or SFN. Besides photofrin, 5-aminolevulinic acid (ALA) is photosensitizer approved for clinical use. Administered ALA is converted to active photosensitizer, protoporphyrin IX (PpIX) in the body (Wachowska et al. 2011). PDT using ALA as a photosensitizer is applied for the treatment of skin cancer, actinic keratosis, and other skin lesions (Cairnduff et al. 1994; Angell-Petersen et al. 2006). In the study of combination of SFN and ALA-PDT, combination treatment did not enhanced the cytotoxicity on cancer cells but increased the synthesis of PpIX in the skin (Mikolajewska et al. 2008).

The mechanism of ROS generation is classified into two kinds of reactions. In type I reaction, the radicals such as superoxide anion radical $\left(\mathrm{O}_{2}{ }^{-}\right)$, hydrogen peroxide $\left(\mathrm{H}_{2} \mathrm{O}_{2}\right)$, or hydroxyl radical $\left(\mathrm{OH}^{-}\right)$are produced. In type II reaction, highly reactive singlet oxygen $\left({ }_{1} \mathrm{O}_{2}\right)$ is formed (Henderson and Dougherty 1992; Dolmans et al. 2003). SA is a specific quencher of singlet oxygen. In our study, ROS generation was highly increased in PDT+SFN group and administration of $\mathrm{SA}$ in $\mathrm{PDT}+\mathrm{SFN}$ group reduced the ROS production as shown in Fig. 3 and 4. Also, PDT+SFN group treated with
SA showed reduced apoptosis and necrosis. These results confirmed that combination of PDT and SFN promoted induction of ROS and this increased ROS production increased cytotoxiciy on cancer cells in PDT+SFN group.

Activation of downstream caspase pathway is critical process of apoptosis. Caspase- 8 and caspase-10, ortholog of caspase- 8 , are initiators of extrinsic pathway. Caspase- 9 is common initiator of intrinsic pathway and caspase- 2 is sometimes involved (Boatright and Salvesen 2003). Caspase- 3 is the finial executor of apoptosis. After the caspase-3 activation, PARP are cleaved, and eventually lead to apoptosis ( $\mathrm{He}$ et al. 2009). Although many apoptotic mechanism induced by PDT are known to targeting a mitochondria (Kessel and Luo 1999; Lam et al. 2001), extrinsic pathway involvement was also reported (Ahmad et al. 2000). In our study, expression of both caspase- 8 and -9 increased. This means both intrinsic and extrinsic pathways are activated. And decreased expression of caspase series in SA-treated cells indicates that ROS generation played the critical role in cell death.

In conclusion, PDT combined with SFN showed enhanced cytotoxic effect on AMC-HN3 human head and neck cancer cells compared to PDT only. Also, enhanced cytotoxicity of combination treatment was derived from in-

A
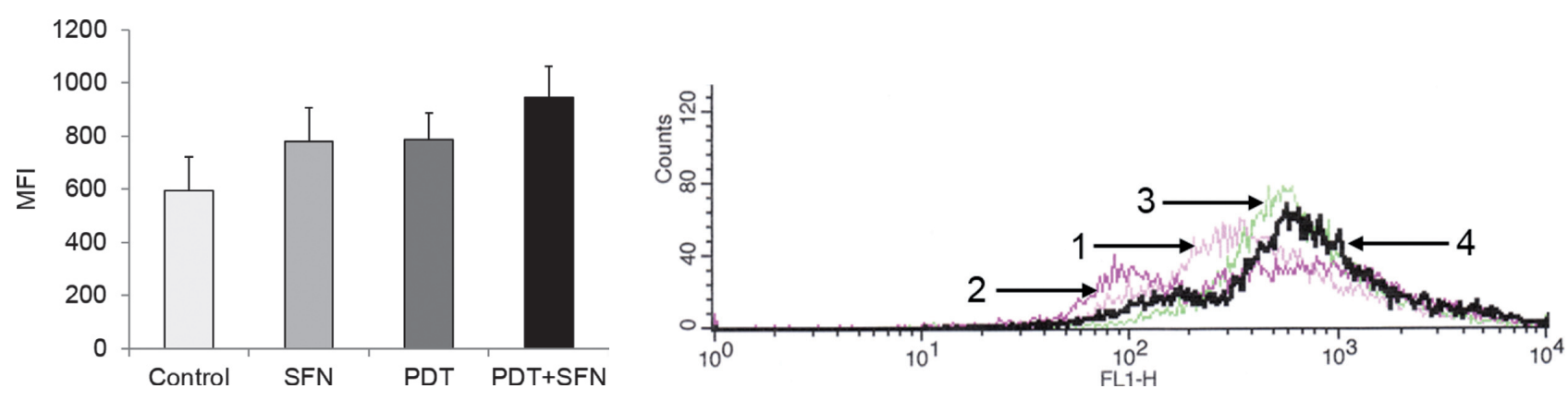

\section{B}
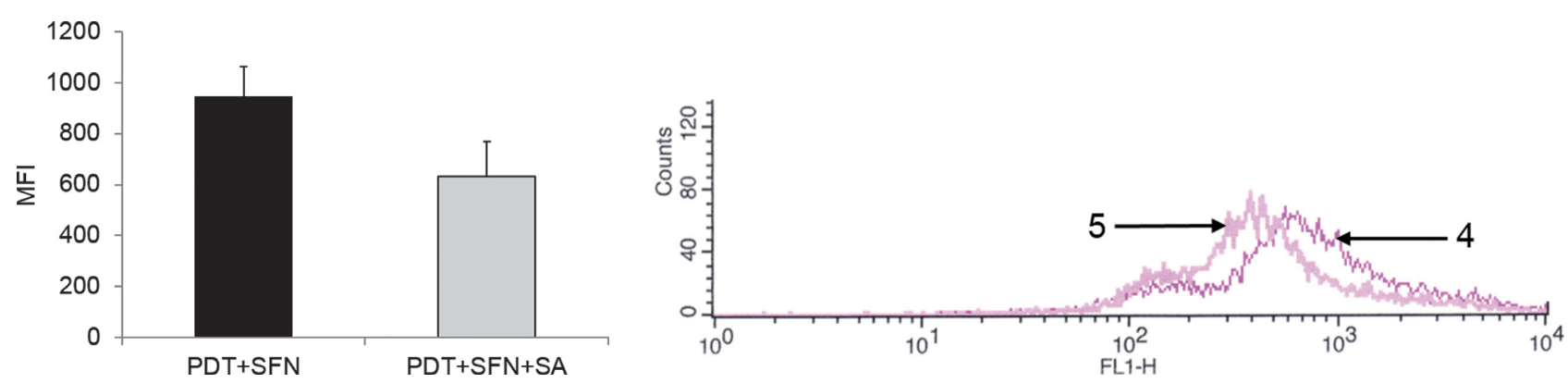

Figure 4. FACS measurement of ROS generation. A. PDT+SFN group showed the highest mean fluorescence intensity (MFI) compared to SFN or PDT groups. B. The SA-treated PDT+SFN group showed lower MFI than untreated PDT+SFN group. SFN, sulforaphane; PDT, photodynamic therapy. FL1-H, $530 \mathrm{~nm}$ fluorescence channel of FACS system; SFN, sulforaphane; PDT, photodynamic therapy; 1, Control; 2, SFN group; 3, PDT group; 4, PDT+SFN group; 5, SA-treated PDT+SFN group. 


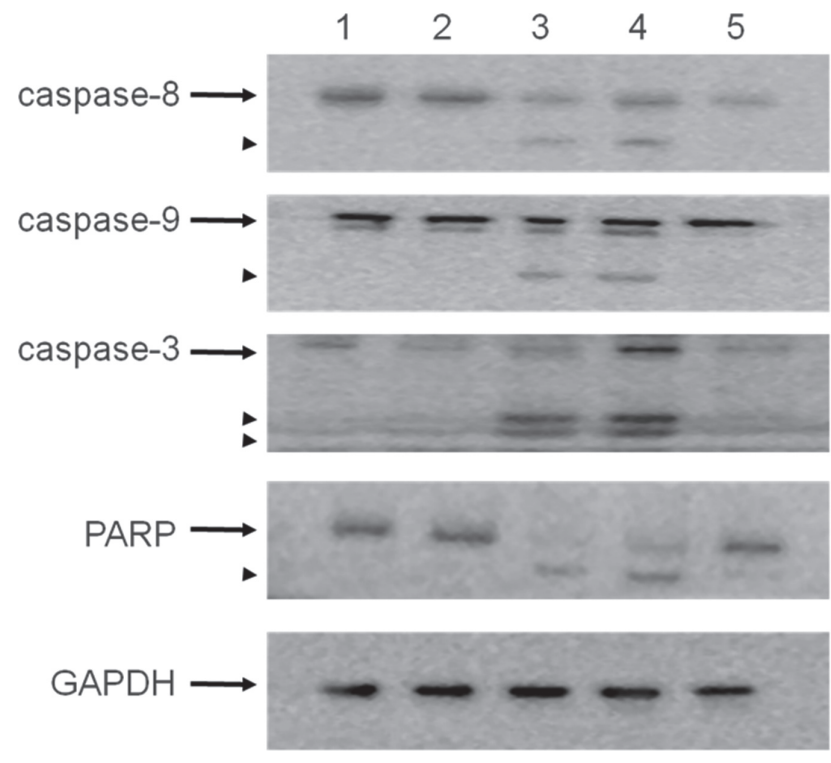

Figure 5. Expression of caspase- $3,-8,-9$ and PARP by Western blotting. Expression of caspase-3, -8 -9 and PARP was the highest in PDT+SFN group, suggesting that caspase pathway was strongly activated in PDT+SFN group. Enhanced expression of caspase proteins was inhibited when ROS was blocked by SA in PDT+SFN group. SFN, sulforaphane; PDT, photodynamic therapy; PARP, poly(ADP-ribose) polymerase; GAPDH, Glyceraldehyde 3-phosphate dehydrogenase; 1 , Control; 2, SFN group; 3, PDT group; 4, PDT+SFN group; 5, SA-treated PDT+SFN group.

crease of ROS generation. The mechanism of cell death was related to the initiation of caspase pathway by ROS and both intrinsic and extrinsic caspase pathways are involved.

Acknowledgements. This work has been supported by Medical Laser Research Center, College of Medicine, Dankook University, Cheonan, Chungnam, Korea.

\section{References}

Ahmad N., Gupta S., Feyes D. K., Mukhtar H. (2000): Involvement of Fas (APO-1/CD-95) during photodynamic therapy-mediated apoptosis in human epidermoid carcinoma A431 cells. J. Invest. Dermatol. 115, 1041-1046 http://dx.doi.org/10.1046/j.1523-1747.2000.00147.x

Allison R. R., Mang T. S., Wilson B. D. (1998): Photodynamic therapy for the treatment of nonmelanomatous cutaneous malignancies. Semin. Cutan. Med. Surg. 17, 153-163 http://dx.doi.org/10.1016/S1085-5629(98)80008-4

Angell-Petersen E., Sorensen R., Warloe T., Soler A. M., Moan J., Peng Q., Giercksky K. E. (2006): Porphyrin formation in actinic keratosis and basal cell carcinoma after topical application of methyl 5-aminolevulinate. J. Invest. Dermatol. 126, 265-271 http://dx.doi.org/10.1038/sj.jid.5700048
Berg K., Moan J. (1997): Lysosomes and microtubules as targets for photochemotherapy of cancer. Photochem. Photobiol. 65, 403-409 http://dx.doi.org/10.1111/j.1751-1097.1997.tb08578.x

Biel M. A. (1998): Photodynamic therapy and the treatment of head and neck neoplasia. Laryngoscope 108, 1259-1268 http://dx.doi.org/10.1097/00005537-199809000-00001

Boatright K. M., Salvesen G. S. (2003): Mechanisms of caspase activation. Curr. Opin. Cell. Biol. 15, 725-731 http://dx.doi.org/10.1016/j.ceb.2003.10.009

Cairnduff F., Stringer M. R., Hudson E. J., Ash D. V., Brown S. B. (1994): Superficial photodynamic therapy with topical 5-aminolaevulinic acid for superficial primary and secondary skin cancer. Br. J. Cancer 69, 605-608 http://dx.doi.org/10.1038/bjc.1994.112

Chiao J. W., Chung F. L., Kancherla R., Ahmed T., Mittelman A., Conaway C. C. (2002): Sulforaphane and its metabolite mediate growth arrest and apoptosis in human prostate cancer cells. Int. J. Oncol. 20, 631-636

Choi W. Y., Choi B. T., Lee W. H., Choi Y. H. (2008): Sulforaphane generates reactive oxygen species leading to mitochondrial perturbation for apoptosis in human leukemia U937 cells. Biomed. Pharmacother. 62, 637-644 http://dx.doi.org/10.1016/j.biopha.2008.01.001

Dolmans D. E., Fukumura D., Jain R. K. (2003): Photodynamic therapy for cancer. Nat. Rev. Cancer 3, 380-387 http://dx.doi.org/10.1038/nrc1071

Dougherty T. J., Gomer C. J., Henderson B. W., Jori G., Kessel D., Korbelik M., Peng Q. (1998): Photodynamic therapy. J. Natl. Cancer. Inst. 90, 889-905 http://dx.doi.org/10.1093/jnci/90.12.889

Gamet-Payrastre L., Li P., Lumeau S., Cassar G., Dupont M. A., Chevolleau S., Gasc N., Tulliez J., Tercé F. (2000): Sulforaphane, a naturally occurring isothiocyanate, induces cell cycle arrest and apoptosis in HT29 human colon cancer cells. Cancer. Res. 60, 1426-1433

He P., Ahn J. C., Shin J. I., Hwang H. J., Kang J. W., Lee S. J., Chung P. S. (2009): Enhanced apoptotic effect of combined modality of 9-hydroxypheophorbide alpha-mediated photodynamic therapy and carboplatin on AMC-HN-3 human head and neck cancer cells. Oncol. Rep. 21, 329-334

Henderson B. W., Dougherty T. J. (1992): How does photodynamic therapy work? Photochem. Photobiol. 55, 145-157 http://dx.doi.org/10.1111/j.1751-1097.1992.tb04222.x

Keller G. S., Doiron D. R., Fisher G. U. (1985): Photodynamic therapy in otolaryngology-head and neck surgery. Arch. Otolaryngol. 111, 758-761 http://dx.doi.org/10.1001/archotol.1985.00800130090012

Kessel D., Woodburn K., Henderson B. W., Chang C. K. (1995): Sites of photodamage in vivo and in vitro by a cationic porphyrin. Photochem. Photobiol. 62, 875-881 http://dx.doi.org/10.1111/j.1751-1097.1995.tb09150.x

Kessel D., Luo Y. (1999): Photodynamic therapy: a mitochondrial inducer of apoptosis. Cell. Death. Differ. 6, 28-35 http://dx.doi.org/10.1038/sj.cdd.4400446

Kim S. Y., Chu K. C., Lee H. R., Lee K. S., Carey T. E. (1997): Establishment and characterization of nine new head and neck cancer cell lines. Acta. Otolaryngol. 117, 775-784 
http://dx.doi.org/10.3109/00016489709113477

Kim H., Kim E. H., Eom Y. W., Kim W. H., Kwon T. K., Lee S. J., Choi K. S. (2006): Sulforaphane sensitizes tumor necrosis factor-related apoptosis-inducing ligand (TRAIL)-resistant hepatoma cells to TRAIL-induced apoptosis through reactive oxygen species-mediated up-regulation of DR5. Cancer. Res. 66, 1740-1750 http://dx.doi.org/10.1158/0008-5472.CAN-05-1568

Lam M., Oleinick N. L., Nieminen A. L. (2001): Photodynamic therapy-induced apoptosis in epidermoid carcinoma cells. Reactive oxygen species and mitochondrial inner membrane permeabilization. J. Biol. Chem. 276, 47379-47386 http://dx.doi.org/10.1074/jbc.M107678200

Mikolajewska P., Juzeniene A., Moan J. (2008): Effect of (R)L-sulforaphane on 5-aminolevulinic acid-mediated photodynamic therapy. Transl. Res. 152, 128-133 http://dx.doi.org/10.1016/j.trsl.2008.07.004

Nishikawa T., Tsuno N. H., Tsuchiya T., Yoneyama S., Yamada J. Shuno Y., Okaji Y., Tanaka J., Kitayama J., Takahashi K., Nagawa H. (2009): Sulforaphane stimulates activation of proapoptotic protein bax leading to apoptosis of endothelial progenitor cells. Ann. Surg. Oncol. 16, 534-543 http://dx.doi.org/10.1245/s10434-008-0215-5

Pass H. (1993): Photodynamic therapy in oncology: mechanisms and clinical use. J. Natl. Cancer. Inst. 85, 443-456 http://dx.doi.org/10.1093/jnci/85.6.443

Rechtman E., Ciulla T. A., Criswell M. H., Pollack A., Harris A. (2002): An update on photodynamic therapy in age-related macular degeneration. Expert. Opin. Pharmacother. 3, 931-938 http://dx.doi.org/10.1517/14656566.3.7.931

Rigual N. R., Thankappan K., Cooper M., Sullivan M. A., Dougherty T., Popat S. R., Loree T. R., Biel M. A., Henderson B. (2009): Photodynamic therapy for head and neck dysplasia and cancer. Arch. Otolaryngol. Head. Neck. Surg. 135, 784-788 http://dx.doi.org/10.1001/archoto.2009.98

Singh S. V., Srivastava S. K., Choi S., Lew K. L., Antosiewicz J., Xiao D., Zeng Y., Watkins S. C., Johnson C. S., Trump D. L., Lee Y. J., Xiao H., Herman-Antosiewicz A. (2005): Sulforaphane-induced cell death in human prostate cancer cells is initiated by reactive oxygen species. J. Biol. Chem. 280, 19911-19924

http://dx.doi.org/10.1074/jbc.M412443200

Takahashi H., Itoh Y., Miyauchi Y., Nakajima S., Sakata I., IshidaYamamoto A., Iizuka H. (2003): Activation of two caspase cascades, caspase 8/3/6 and caspase 9/3/6, during photodynamic therapy using a novel photosensitizer, ATX-S10(Na), in normal human keratinocytes. Arch. Dermatol. Res. 295, 242-248 http://dx.doi.org/10.1007/s00403-003-0424-5

Wachowska M., Muchowicz A., Firczuk M., Gabrysiak M., Winiarska M., Wańczyk M., Bojarczuk K., Golab J. (2011): Aminolevulinic acid (ALA) as a prodrug in photodynamic therapy of cancer. Molecules 16, 4140-4164 http://dx.doi.org/10.3390/molecules 16054140

Received: July 7, 2014

Final version accepted: August 14, 2014

First published online: November 14, 2014 